\title{
Developing Visual Novel Game with Speech-Recognition Interactivity to Enhance Students' Mastery on English Expressions
}

\author{
Elizabeth Anggraeni Amalo, Imam Dui Agusalim, Citra Devi Murdaningtyas \\ Politeknik Elektronika Negeri Surabaya \\ Kampus PENS, Jalan Raya ITS Sukolilo, Surabaya 60111 \\ Tel: (031) 594 7280; Fax: (031) 5946114

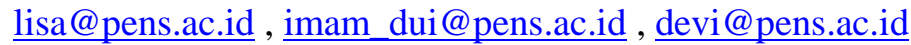

Diterima: 16 Agustus 2017

Direview: 26 Agustus 2017

Diterbitkan: 30 November 2017

Hak Cipta @ 2017 oleh Penulis (dkk) dan Jurna Sosial Humaniora (JSH)

*This work is licensed under the Creative

Commons Attribution International License (CC BY 4.0).

http://creativecommons.org/licenses/by/4.0/
Subject Areas: language, visual novel game

\begin{abstract}
The teaching of English-expressions has always been done through conversation samples in form of written texts, audio recordings, and videos. In the meantime, the development of computer-aided learning technology has made autonomous language learning possible. Game, as one of computer-aided learning technology products, can serve as a medium to provide educational contents like that of language teaching and learning. Visual Novel is considered as a conversational game that is suitable to be combined with English-expressions material. Unlike the other click-based interaction Visual Novel Games, the visual novel game in this research implements speech recognition as the interaction trigger. Hence, this paper aims at elaborating how visual novel games are utilized to deliver Englishexpressions with speech recognition command for the interaction. This research used Research and Development $(R \& D)$ method with Experimental design through control and experimental groups to measure its effectiveness in enhancing students' English-expressions mastery. ANOVA was utilized to prove the significant differences between the control and experimental groups. It is expected that the result of this development and experiment can devote benefits to the English teaching and learning, especially on English-expressions.
\end{abstract}

Keywords: computer-aided learning; Teaching English; Visual Novel games; conversation; expressions.

\section{Introduction}

Communication is what language like English is for (Waterson, 2008). For those who believe in behavioral approach, language practices in form of drilling become much of the solution (Richards, 2005). As a result, English expressions like greetings, apologizing, congratulating, and the like are taught for conversation practice, and are considered as real communications (Davies \& Pearse, 2000). Thus, Language expressions such those become one part of teaching materials in most academic levels of English curriculum in countries like Indonesia where English serves second language or foreign language.

Based on the observation conducted in some senior high schools, English expressions like greetings, apologizing, and the like have been presented through providing conversation samples in form of printed texts, audio recordings, and videos. The teachers usually implement conversation practice in which a student is partnering with a peer, demonstrating the sample conversation already served by the English textbooks. In addition, the 
teachers sometimes encourage the students to develop their own conversation script containing English expressions and then to demonstrate it. The assessment the teachers frequently implemented to evaluate the students' achievement in English expressions was through written test.

These practices, in which English expressions are given through written conversation samples, audio recordings, videos; and are assessed through written test, or sometimes through oral test, have been experienced by students across their academic levels from elementary, junior high school, and senior high school. As a result, as what most teachers suspect, students tend to start experiencing boredom of having been through similar practices. Regarding with this problem, the teachers demand another form of teaching medium to deliver English expressions materials to the students.

Responding to this expectation, Muhammad (2016) combined computer aided learning technology with educational contents by developing and experimenting a visual novel game associated with conversation gambits containing English expressions. Computer game, as one form of computer aided learning advancements, is able to motivate students to be involved in learning processes (Liu \& Chu, 2010). The visual novel game in the study of Muhammad (2016) presents in a form of dialog branches utilizing English expressions and conversation gambits as the options of responses by the player. The game play involves the steps including player selects a mission to accomplish, and follows the dialog branching by choosing offered responses. Each response leads to different results, either successful or failed. The effectiveness of the visual novel game was experimentally assessed through control and experimental groups. It resulted that it brought significant improvement on the achievement but less significant increase on the motivation.

The interaction used in Muhammad (2016) was click button. As Muhammad's suggestion, future researcher was encouraged to utilize speech recognition as interaction so that the conversation feels like real. Speech recognition has been used for many purposes of interaction. One of simple implementations is that used by Wardhany, et. al. (2014).

Thus, this research aimed at answering the following research question:

Do students taught using the Visual Novel Game with speech recognition interactivity have higher achievement on English expression than those taught using conventional method?

In response to the research question, the following hypothesis was proposed:

There is significant difference on the students' English expressions mastery between experimental and control group.

\section{Related Works}

This research and development is related to some previous studies concerning with computeraided learning in form of games like visual novel for educational purposes in general, and teaching and learning English in particular.

Emi \& Okuda (2016) developed an EPUB-type visual novel to deliver math subjects. Math teaching materials, as educational content, was embedded into the story of the visual novel. Math involves conceptual and practical approach. This visual novel was designed more on delivering conceptual math 
contents. Experimental research design was implemented to find out the significant impact of this visual novel to students' motivation.

This research was also encouraged by the formerly interrelated research directed by Dieni (2014). The research was concerning the effectiveness of visual novel game to teach writing regarded with students' innovation. The research utilized experiment and control group. The experiment group utilized visual novel game to guide students' writing class, while the control group made use of pictures. The finding recommends that there resulted insignificant increase between the treatment and the control group.

This research was also done to regard research findings inconsistency, mostly associated to the effectiveness of games to increase scores and motivations through teaching materials and topics.

This paper was to strengthen the previous research results by examining the effectiveness of computer games, particularly visual novel game, toward students' achievement on learning English expressions.

\section{Originality}

The idea of utilizing speech recognition as a medium for interactivity in visual novel game has never been implemented before, knowing that the remaining visual novel games are click-based interaction. Thus, the development of the visual novel game in this study stands on its novelty.

Unlike other existing visual novels, the visual novel developed in this study shows the following differences (Table 1).

Speech recognition is utilized as interaction medium, replacing button click as used in the remaining visual novel games. The consideration in using this type of interaction deals with facilitating the role of language as spoken medium of communication. In real life usage, Englishexpressions are used for communication. Thus, speech recognition as the main interaction will bring the sense of real communication.

\section{System Design}

Visual novel game in this study was composed of elements namely (1) visual assets including background and character graphics, (2) audio assets including characters' voice over, background music, and audio effects, (3) branching dialogue, (4) grading system, and (5) interactivity.

The visual assets were composed with manga style, common graphical style for most visual novels. The voice over audio, recorded from the real voices of native English talents, represents the characters' responses to the player.

The dialog branching was developed within each task of each mission that connects the whole story of the game. The dialog flow was similar to adventure game like choose your own story games in which each response represents different consequence for either successful or unsuccessful. Each success or fail is recorded as point for grading. The main story map is shown in Figure 2.

In the game, the player is given response options. The difference between common visual novel game and this visual novel game is that this game uses speechrecognition to trigger the button, while other visual novel games use mouse-click to trigger the button. The conversation system in which speech-recognition is processed as the interaction is shown in Figure 1. A user gives voice input that is converted as text and is assigned as keyword. If the words match with the pass keywords based on the question by the 
character, then the button will be activated and answered by the computer through the character.

\section{Results}

The effectiveness of visual novel game developed in this research in enhancing students' mastery of English expressions was examined through experimental design. Control and experimental groups were assigned with different treatments. The control group was given the existing learning source, while the experimental group was given the visual novel game as the learning source. The posttest was conducted to see the increase after each treatment.

The achievement increase of each group was then compared to reveal the difference. The raw test result of both groups is shown in Table 1. The flow of this experiment is elaborated in Table 2.

\section{Research Subjects}

The research subjects of this study were two classes in Politeknik Elektronika Negeri Surabaya (PENS), which were assigned as control group with 27 students, and experimental group with 28 students of Multimedia Broadcasting, one of majors in PENS. The two classes were considered as equal because they were distributed based on the results of admission test conducted by PENS. The admission test resulted 55 students, comprising 15 students above average score, 28 students in average score, and 12 students of below average score. They were then assigned to class A and B. Class A consists of 8 students above average score, 14 students in average score, and 6 students of below average score. The remaining numbers were assigned into class $\mathrm{B}$.

\section{Treatments}

Control and experimental group received different treatments. The control group was given lesson on English expressions through conventional method in which the lecturer used printed materials for students to learn English expressions. The experimental group used visual novel with speechrecognition based interaction. The detail of each treatment is shown in Table 3.

\section{Instruments}

As this research aimed at examining the effects of the visual novel game towards students' achievement. Achievement test was used to see the students' mastery on English expressions.

The achievement test was the test developed by the Team of English lecturers in PENS. The test consisted of English expression mastery in form of multiple-answer questions. The test was tested for its reliability by the team. The reliability was measured using Anates v.4 for windows through split-half method with Pearson's Product Moment and the reliability score shows 0.79 , which is considerably high (Arikunto, 2009).

\section{Achievement Results}

To find out whether the experimental group significantly achieved higher score than the control group, the posttest results of both groups were compared. As the number of students in each group was less than 30, ANOVA was implemented to reveal the significant increase.

$P$ value and statistical significance: The twotailed $\mathrm{P}$ value is less than 0.0001 . By conventional criteria, this difference is considered to be statistically significant. Confidence interval: The mean of Experiment minus Control equals 10.85. 95\% 
confidence interval of this difference: From 6.11 to 15.59. Intermediate values used in calculations: $t=$ 24.5920. $\mathrm{df}=53$. Standard error of difference $=$ 2.363. The data is shown in Table 4 .

Table 1. Raw Posttest Score of Experimental and Control groups

\begin{tabular}{|c|c|c|c|}
\hline No & Experimental Group & No & Control Group \\
\hline 1 & 78 & 1 & 77 \\
\hline 2 & 69 & 2 & 67 \\
\hline 3 & 82 & 3 & 78 \\
\hline
\end{tabular}

Table 2. Uniqueness of visual novel game developed in this research

\begin{tabular}{|c|c|c|}
\hline Aspects & Other Visual Novels & Visual Novel in this study \\
\hline Interaction & Button Click & Speech Recognition \\
\hline Content & General Stories & $\begin{array}{c}\text { Specifically Combined with } \\
\text { Educational Content }\end{array}$ \\
\hline
\end{tabular}


Table 3. Experimental Research Design

\begin{tabular}{|l|l||l|}
\hline Groups & Treatments (4 weeks) & Test \\
\hline \multirow{3}{*}{ Experimental } & $\begin{array}{l}\text { Visual Novel Game } \\
\text { Week 1. Class room }\end{array}$ & \\
teaching & $\begin{array}{l}\text { English } \\
\text { Week 2. Playing Game } \\
\text { achievement test }\end{array}$ \\
& Week 3. Playing Game & \\
\hline
\end{tabular}

Table 4. Unpaired T-test result

\begin{tabular}{|c|c|c|}
\hline Group & Experiment & Control \\
\hline Mean & 77.46 & 73.15 \\
\hline SD & 7.75 & 6.70 \\
\hline SEM & 1.47 & 1.29 \\
\hline N & 28 & 27 \\
\hline
\end{tabular}

Conversation system

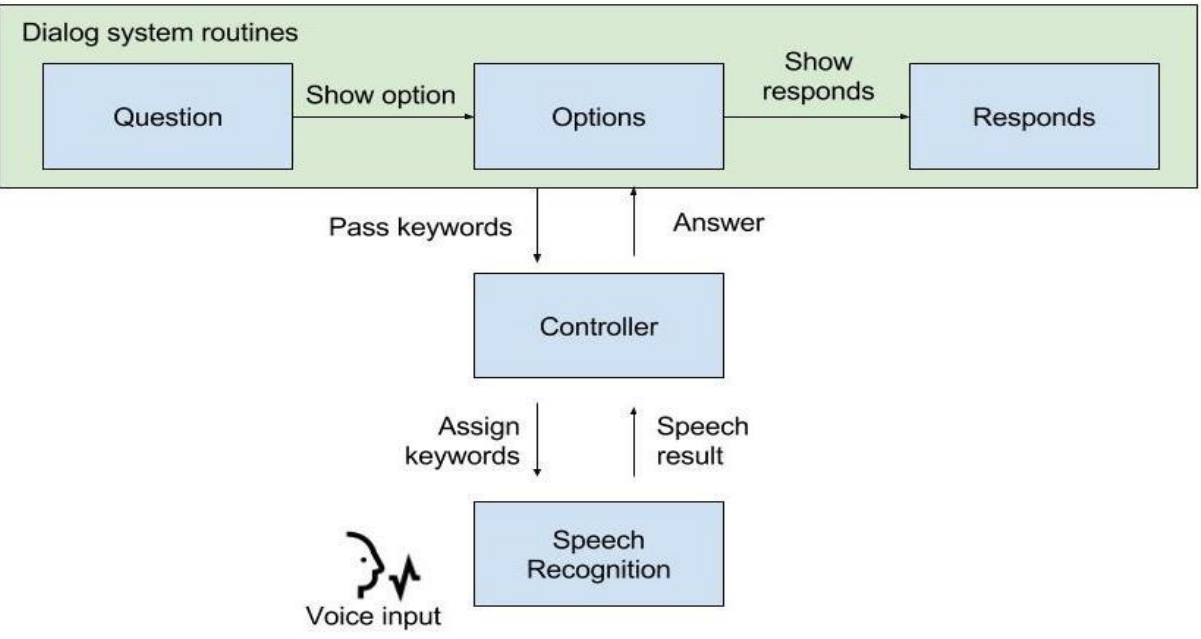

Figure 1. Conversation System 


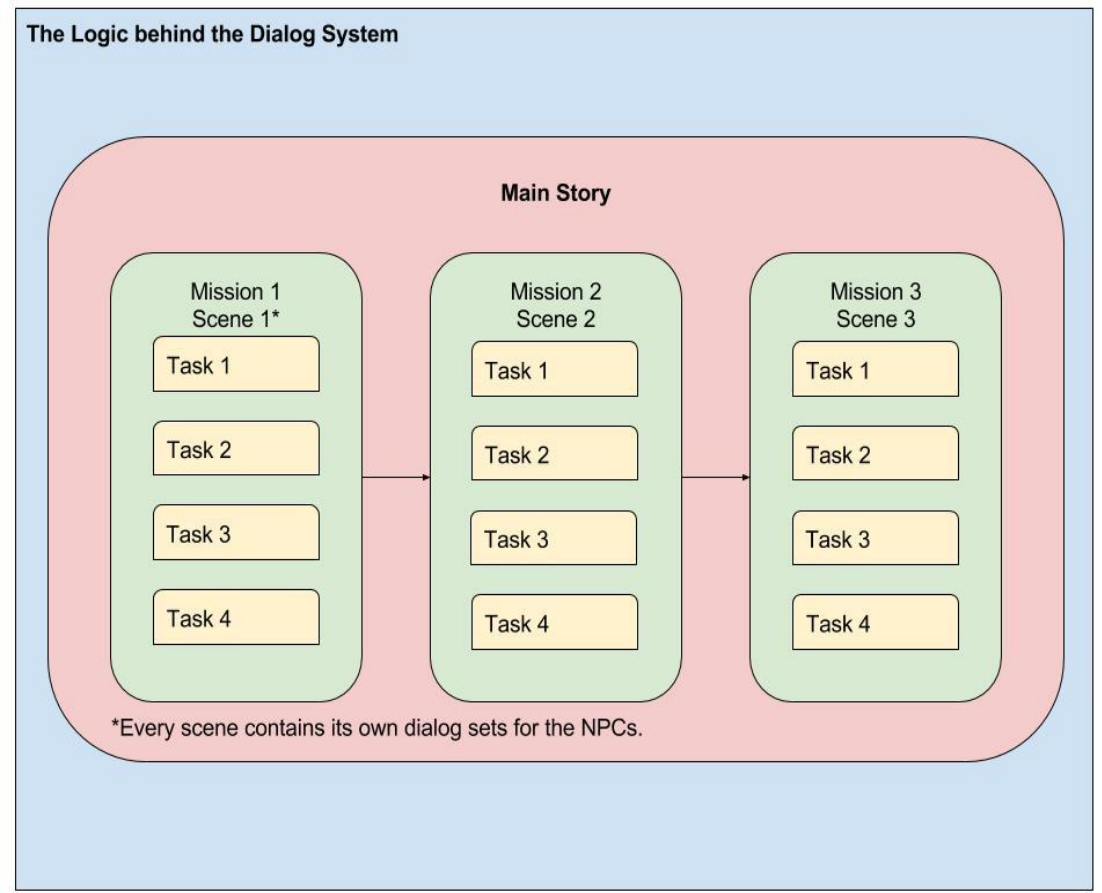

Figure 2 Dialog System

\section{Conclusion}

The Visual Novel Game with speech recognition interactivity significantly donated constructive outcomes toward students' achievement in mastering English expressions. As a consequence of implementing visual novel game with speech recognition interactivity, the experimental group showed higher achievement than did the control group, while the posttest results of both group were significantly higher than their pretest results.

Cornillie, Clarebout \& Desmet (2012) explained that, in terms of educational purposes, learning while playing game contributed robust connection. Although games do not explicitly hold learning materials, they positively influenced learning, especially for particular subject matter. Suh, Kim \& Kim (2010) reported that games significantly influenced students' motivation in learning English.
There is a chance for games to be applied as additional medium for students to acquire learning materials other than in classrooms. Hung, Yong \& Lin (2015) confirmed that games effectively reduce gaps in terms of students' achievement as outside classroom, students can outperform autonomously.

\section{Suggestion}

As a suggestion for further research, it is encouraged that learning material be integrated with games. Fasli \& Michalakopoulos (2005) and Gros (2007) claimed that in order to support active learning, games may be utilized as medium to deliver school contents, regardless of their possible obstructions.

In the future, data of students' participation in using this visual novel game can be recorded to measure students' learning activity Rachmawan et.al. (2016). 


\section{References}

Arikunto, Suharsimi. 2009. Dasar-dasar Evaluasi Pendidikan. Aneka Cipta: Jakarta

Cornillie, F., Clarebout, G., \& Desmet, P. Between learning and playing? Exploring learners' perceptions of corrective feedback in an immersive game for English Pragmatics. ReCALL, 24(3), pp. 257-278.

Davies, P., \& Pearse,E. (2000). Success in English Teaching: A Complete Introduction to Teaching English at Secondary School Level and Above. Oxford: Oxford University Press.

Dieni, N. A. I. (2014). The effectiveness of visual novel to teach writing viewed from students' creativity (an experimental study at the seventh grade students of SMP Al-Islam Surakarta in the academic year of 2013/2014). (Unpublished Doctoral dissertation). Universitas Sebelas Maret, Surakarta.

Emi, K., \& Okuda, S. (2016). EPUB-type visual novel gives us happy math: A prototype of edutainment software on math. IEEE 5th Global Conference on Consumer Electronics, Kyoto, Japan.

Fasli, M., \& Michalakopoulos, M. (2015). Supporting active learning through gamelike exercises. $5^{\text {th }}$ IEEE International Conference on Advanced Learning Technologies (ICALT'05), pp. 730-734.

Gros, B. (2007). Digital games in education: The design of games-based learning environments. Journal of Research on Technology in Education, 40(1), pp. 23-38.

Hung, H. C., Young, S. S. C., \& Lin, C. P. (2015).

No student left behind: A collaborative and competitive game-based learning environment to reduce the achievement gap of EFL students in Taiwan. Technology, Pedagogy and Education, 24(1), pp. 35-49.

Liu, TY., \& Chu YL. (2010). Using ubiquitous games in an English listening and speaking course: Impact on learning outcomes and motivation. Computers \& Education 55(2), 630-643.

Muhammad, A. F. (2016). The effects of conversation-gambits visual-novel game on students' English achievement and motivation, International Electronics Symposium (IES), Denpasar, pp. 481-486.
Rachmawan I.E.W., Fahmi, N., Widodo, E.W., Huda, S., Pamenang, M.U., Roziqin, M.C., Permana,A., Sukaridhoto, S., \& Pramadihanto, D. (2016). An Embedded System for applying High Performance Computing in Educational Learning Activity. EMITTER International Journal of Engineering Technology, 4 (1), June.

Richards, J. C. (2005) Communicative language teaching today. Singapore: SEAMEO Regional Language Centre.

Suh, S., Kim, S. W., \& Kim, N. J. (2010). Effectiveness of MMORPG-based instruction in elementary English education in Korea. Journal of Computer Assisted Learning, 26(5), pp. 370-378.

Wardhany, V.A., Sukaridhoto, S., \& Sudarsono, A. (2014). Indonesian Automatic Speech Recognition for Command Speech Controller Multimedia Player. EMITTER International Journal of Engineering Technology 2(2), December.

Watterson, M. (2008). Repair of non-understanding in English in international communication. World Englishes, 27(3-4), pp. 378-406. 